\title{
A Study Comparing Chemical Peeling using Trichloroacetic Acid and Jessner's Solution in the Treatment of Melasma
}

\author{
Moustafa M. Eyada, Rabie A. Abo bakr, Shereen F. El-Saman*, \\ Rania A. Abd El-Naby \\ Dermatology \&Venereology Dept., Faculty of Medicine, Suez Canal University, Ismailia, Egypt.
}

\begin{abstract}
Background: Melasma is a symmetric progressive hyperpigmentation of the facial skin. TCA and Jessner's peel solution are the most popular peeling agents used and most commonly used for superficial and medium depth peels. Aim: is to compare the efficacy and complications of both Trichloroacetic acid $25 \%$ and Jessner's peel solution in the treatment of melasma. Methods: Our study included 29 patients with melasma. Patients were subjected to wood's light to determine the melasma type as the epidermal melasma were included in this study. Split face approach was used as TCA was applied on the right side of the face, and standard jessner's solution was applied on the left side of the face. Every patient had pre peeling preparation period of 2 weeks, sessions were carried out every 2 weeks (each patient had 6 sessions and was followed-up for 3 months). Melasma Area and Severity Index (MASI) were used for clinical evaluation. MASI was recorded in the first visit (baseline score), at the end of the sessions and after the follow up period. Results: There were no statistically significant differences between the two studied methods of treatment regarding degree of improvement according to physicians, patients or blinded observer ( $p>0.05)$. Also, there were no statistically significant difference between both studied methods of treatment regarding mean MASI score at baseline $(p>0.05)$. TCA treated side showed highly significant lower mean MASI score after the end of sessions than Jessner's solution treated side $(4.9 \pm 2.7$ vs. 5.5 \pm 2.7$)$ ( $p<0.01)$. Conclusion: Our findings suggest that either TCA or Jessner's solution can be effectively used to treat melasma.
\end{abstract}

Keywords: TCA, Jessner's solution, Melasma.

\section{Introduction}

Melasma is an acquired hypermelanosis of sun exposed areas. It presents usually as symmetric hyperpigmented macules, which can be confluent or punctuate. The cheeks, the bridge of the nose, the forehead, the upper lip and the chin are the most common locations. Women are predominantly affected, although it occasionally occurs in men. Chloasma is a synonymous term used sometimes to describe the occurrence of melasma during pregnancy. The cause of melasma is multifactorial and includes racial, genetic predisposition, exposure to sunlight and hormonal influences as pregnancy, lactation, contraceptive pills, estrogen plus progesterone as replacement therapy in post menopause medications and endocrine dysfunction. Melasma is more common in brown skin types, especially Asians and Hispanics, and areas of the world with intense sun exposure ${ }^{(1)}$. Every case of melasma starts in the epidermis, where melanocytes are actively producing pig-

*Corresponding Author: shereenfkry@hotmail.com 
ment. If the skin is over irritated and inflamed the melasma become dermal, by a temporary split between the dermis and the epidermis. During this time, hyperpigmented cells can drop from the epidermis into the dermis. Once in the dermis, these cells become very resistant to topical treatment. Melasma is either epidermal, dermal, or mixed epidermal and dermal which is the most common type. Clinical examination of melasma under wood's light (wavelength, $365 \mathrm{~mm}$ ) helps to determine the location of melanin in the skin as the epidermal form is enhanced under wood's light whereas the dermal form shows no enhancement ${ }^{(2)}$.

Therapy for melasma has generally been difficult, particularly in black patients. Therapies have included the routine use of broad spectrum sunscreen and various concentration of hydroquinone with or without the addition of corticosteroids, retinoids (tretinoin), salicylic acid or glycolic acid. In general melasma of recent onset responds better than the long standing cases, and the melasma of epidermal type, as determined by woods light responds faster than the mixed epidermodermal type ${ }^{(3)}$.

Chemical peeling is one of the new weapons in the therapeutic armamentarium of melasma ${ }^{(4)}$. Since the days of ancient Egypt, people have been using chemo exfoliation methods, also known as chemical peeling, to rejuvenate skin. The original chemoexfoliant was lactic acid, an active ingredient of sour milk that was used topically by the nobles as part of an ancient skin rejuvenation regimen. In the middle ages, old wine with tartaric acid as its active ingredient was used for the same purpose; the chemical peel produces a controlled partial thickness injury to the skin. Following the insult to the skin, a wound healing process ensues that can regenerate epidermis from surrounding epithelium and adnexal structures, decrease solar elastosis, and replace and reorient the new dermal connective tissue. The result is an improved clinical appearance of the skin, with fewer rhytides and decreased pigmentary dyschromia ${ }^{(5)}$.

Several chemical peeling agents were used in treatment of melasma. Superficial and medium depth peels with trichloroacetic acid (TCA), glycolic acid, salicylic acid and Jessner's solution benefit some individuals. The addition of these agents to a modified Kligman's formula displayed more rapid and greater improvement than the topical regimen alone ${ }^{(6)}$. Indications of superficial peels include skin resurfacing, wrinkles, actinically damaged skin, actinic keratoses and benign pigmented lesions. Superficial peels have the advantage that they can be used on most regions of the $\operatorname{body}^{(7)}$.

TCA (10-25\%) has been used for many years as a superficial peeling agent, and is safe at lower concentrations, at higher concentrations such as $50 \%$ and above, TCA has a tendency to scar formation and is less manageable than other agents used for superficial peels ${ }^{(8)}$. TCA has been well studied and is versatile in its ability to create superficial, medium depth and deep peels. It is stable, inexpensive and causes no systemic toxicity. It is easy to perform, as the peel depth correlates with the intensity of skin frost and there is no need to neutralize a TCA peel ${ }^{(9)}$. Hyperpigmentation is the commonly observed side effect, with superficial peels, especially with $\mathrm{TCA}$, in people living in tropical countries with intense ultraviolet exposure ${ }^{(10}$, ${ }^{11)}$. Jessner's solution has been used for 100 years as therapeutic agent to treat hyperkeratotic epidermal lesions. This superficial peeling agent constitutes a mixture of salicylic acid, resorcinol, and lactic acid in $95 \%$ ethanol. Jessner's solution causes loss of corneocyte cohesion and 
causes intercellular and intracellular edema. Jessner's typically induces wounding to the level of papillary dermis; high concentrations of resorcinol were associated with side effects like allergic contact dermatitis and skin discoloration. Subsequently Jessner's solution was formulated by Dr Max Jessner to lower the concentration of any one agent contained in the mixture and to enhance its overall effect as a keratolytic agent ${ }^{(12)}$. Despite concerns regarding resorcinol and salicylate toxicity, Jessner's solution has been extremely well tolerated with minimal side effects. Allergic reactions to resorcinol are reported to be rare ${ }^{(13)}$. TCA and Jessner's solution are well accepted; there have been no good comparisons between the two agents. The purpose of this study is to assess and compare the efficacy and side effects of TCA and Jessner's solution chemical peeling in the treatment of melasma.

\section{Patients and Methods}

Our study included twenty-nine female patients more than 18 years old with epidermal melasma affecting the face; patients were selected on clinical basis from Dermatology and Venereology outpatient clinic, Suez Canal University hospital during the period from April 2009 to April 2010. A written informed consent was obtained by every patient before the beginning of treatment. Split-face approach was used as TCA was applied to the right side of the face, and standard jessner's solution was applied on the left side of the face. Every patient had pre peeling preparation period of 2 weeks, sessions were carried out every 2 weeks, and every patient had 6 sessions followed by 3 months as a follow up period. Patients excluded from this study were: Pregnancy and females on oral contraceptive pills, dermal or mixed melasma, participants with a his- tory of hypertrophic scars or keloids, recurrent herpes infection or cutaneous infections, endocrinal diseases, poor general health, HIV or hepatitis viral infections, sensitivity to TCA or to any of the Jessner's solution component's and participants with unrealistic expectations regarding peeling procedure outcome ${ }^{(7)}$. Patients included in this study were subjected to the following: Careful history and clinical examination: Full history taking and local skin examination included Melasma Area and Severity Index (MASI) for clinical evaluation. The MASI was recorded in the first visit (baseline score), and at the end of the sessions and during the follow up period ${ }^{(14)}$.

Pre-peeling preparations ${ }^{(9)}$ : Determination of the skin type according to Fitzpatrick's classification system. Baseline photography full-face frontal and lateral photos were taken for each patient at the beginning of the sessions. All patients used topical bleaching agent as hydroquinone $4 \%$ cream and topical retinoid as tazarotene 2 weeks prior to peeling and all patients were advised to use sun screen lotion with SPF of more than 35 per 2 hours daily. The patients were instructed to avoid makeup use for twentyfour hours before the session. A surgical cap covering the hair and the ears were used and the eyes were covered too. The face was cleansed and degreased by Alcohol and acetone, degreasing is important, care must be taken not to abrade the skin as this may cause increased uptake and thus an uneven peel. A post auricular test peel was performed and left for 15-20 minutes to find any hypersensitivity to the peeling agent. All patients were allowed to set in front of a fan if needed.

The steps of the peeling procedure ${ }^{(9)}$ : TCA $25 \%$ was applied to the right side of the face. TCA was painted even Forehead 
to temple to cheeks and finally to the upper lips and eyelids within 1-2 $\mathrm{mm}$ of the lower eyelid margin. Amount of TCA delivered is dependent on: number of applications, degree of saturation and pressure applied to the skin. White frost appeared complete on the treated area within 30 seconds to 2 minutes. Before re-treating an area we waited at least 3-4 minutes before determining for asymmetry. Jessner's solution was applied to the left side of the face by cotton tipped applicator. Application was completed covering the whole area within $30 \mathrm{sec}$., as application of the solution was started from the least sensitive area to the more sensitive area; we started from forehead, cheek, chin, nose, perioral area to the eyelids. Number of coats and the contact time were gradually increased in our study, we started with 3 coats and $2 \mathrm{~min}$. contact time increased up to $5 \mathrm{~min}$. and 5 coats of application or till the frosting appears. The patient experienced a burning sensation that started once the solution was applied. There was a fan blowing on the patient's face to alleviate this discomfort. Patients were generally advised to keep the peeled area moist to promote wound healing. This can be accomplished with an emollient lotion or with other products. Cool compresses and elevation of the head of bed can pro- vide symptomatic relief. Gentle soap and water washings help keep the area clean. The patients were instructed to use sun block with SPF more than 35 per 2 hours daily and avoid sun exposure as Sunscreen is necessary to prevent further actinic damage and to prevent hyperpigmentation. Patients were instructed to avoid manipulation of the treated area.

4- Post peeling evaluation: The results were evaluated by MASI score, improvement from baseline was rated on a fourpoint scale at each visit as following: Excellent $>75 \%$ (if more than $75 \%$ of lesions were resolved), good $>50 \%$ (if more than $50 \%$ of lesions were resolved), fair $<50 \%$ (if less than $50 \%$ of lesions were resolved) and worsening (if there was exacerbation or deterioration of the original disease) ${ }^{(15)}$. Full face frontal and lateral photos were taken for each patient every session; also the photographs were evaluated by at least two other dermatologists. Safety evaluation included the assessment of erythema, discomfort (burning, itching), infection, scaling, dryness, post inflammatory hyperpigmentation. All the participants were evaluated for recurrence of melasma, guided by the MASI score during the follow up period for an average of 3 month after treatment.

Table 1: Outcome measures of TCA and Jessner's peel solution among the studied group

\begin{tabular}{|c|c|c|c|c|c|}
\hline Measures & & $\begin{array}{l}\text { TCA }(n=29) \\
\text { No. }(\%)\end{array}$ & $\begin{array}{c}\text { Jessner's }(n=29) \\
\text { No. }(\%)\end{array}$ & test & $p$ value \\
\hline $\begin{array}{l}\text { Degree of improve- } \\
\text { ment (physicians) }\end{array}$ & $\begin{array}{l}\text { - Excellent } \\
\text { - Good } \\
\text { - Fair }\end{array}$ & $\begin{array}{c}16(55.2) \\
7(24.1) \\
6(20.7)\end{array}$ & $\begin{array}{c}13(44.8) \\
9(31.0) \\
7(24.1)\end{array}$ & $0.64^{\$}$ & 0.73 \\
\hline $\begin{array}{l}\text { Degree of improve- } \\
\text { ment (patients) }\end{array}$ & $\begin{array}{l}\text { - Excellent } \\
\text { - Good } \\
\text { - Fair }\end{array}$ & $\begin{array}{c}16(55.2) \\
10(34.5) \\
3(10.3)\end{array}$ & $\begin{array}{c}13(44.8) \\
13(44.8) \\
3(10.3)\end{array}$ & $0.70^{\$}$ & 0.70 \\
\hline $\begin{array}{l}\text { Degree of improve- } \\
\text { ment (blinded ob- } \\
\text { servers) }\end{array}$ & $\begin{array}{l}\text { - Excellent } \\
\text { - Good } \\
\text { - Fair } \\
\text { - Bad }\end{array}$ & $\begin{array}{c}16(55.2) \\
6(20.7) \\
6(20.7) \\
1(3.4)\end{array}$ & $\begin{array}{c}13(44.8) \\
8(27.6) \\
8(27.6) \\
0\end{array}$ & $1.88^{\xi}$ & 0.60 \\
\hline $\begin{array}{l}\text { MASI score } \\
(\text { mean } \pm \text { SD })\end{array}$ & $\begin{array}{l}\text { - Baseline } \\
\text { - End of sessions } \\
\text { - End of follow up }\end{array}$ & $\begin{array}{l}9.7 \pm 2.3 \\
4.9 \pm 2.7 \\
4.9 \pm 2.7\end{array}$ & $\begin{array}{l}4.9 \pm 2.7 \\
4.9 \pm 2.7 \\
5.5 \pm 2.7\end{array}$ & $\begin{array}{c}0.229^{\#} \\
-3.537^{\#} \\
-1.683^{\#}\end{array}$ & $\begin{array}{l}0.821 \\
0.001^{* *} \\
0.001 * *\end{array}$ \\
\hline
\end{tabular}

**=Highly significant $p$-value at $\leq 0.01 ; \#=T$ test; $\$=\chi^{2}$ 


\section{Results}

Demographic Data: The mean age of patients was $35.5 \pm 9.3$ years with a range of 19-53 years, $89.7 \%$ of them had a history of sun exposure. The majority of the studied patients had family history of melasma (75.9\%). About $62.1 \%$ of the women had a history of hormonal contraceptive method. $51.7 \%$ of patients with Fitzpatrick skin type III while, $41.4 \%$ of them had skin type IV and $6.9 \%$ with skin type V. Regarding the outcome measures of TCA and Jessner's solution peels among the studied women with melasma, there were no statistical significant differences between both studied methods of treatment (TCA and Jessner's solution) regarding degree of improvement according to physicians, patients or blinded observer ( $p>0.05)$. Also, there were no statistical significant difference between both studied methods of treatment (TCA and Jessner's solution) regarding mean MASI score at baseline ( $p>0.05)$. TCA-treated side showed highly significant lower mean MASI score after the end of sessions than Jessner's soluion treated side $(4.9 \pm 2.7$ vs $5.5 \pm 2.7$, respectively) ( $p<0.01$ ) Table (1). Table (2) shows a non-statistically significant differences between both studied methods of treatment (TCA and Jessner's solution) regarding post-peeling erythema, infection, hyper-pigmentation, dryness and swelling ( $p>0.05$ ). TCA group showed highly significant frequency of moderate to severe discomfort (burning and/or itching) than Jessner's solution group (93.1\% versus $41.4 \%$, respectively) ( $p<0.01)$. Also, TCA group showed highly significant frequency of moderate to severe scaling in the TCA side than Jessner's solution-treated side $(96.6 \%$ vs. $55.2 \%)(p<0.01)$.

Clinical results in the right malar area (TCA $25 \%$ only): The average (mean) MASI score in the right malar area before treatment was $9.7 \pm 2.3$, whereas after treatment (at the end of peeling sessions and during follow up period), the average MASI score changed to $4.9 \pm 2.7$, the average decrease in the MASI score was 4.8 , and this represent a $51 \%$ decrease.

Clinical results in the left malar area (Jessner's solution only): The average (mean) MASI score in the left malar area before treatment was 9.7 \pm 2.3 , whereas after treatment (at the end of peeling sessions and during follow up period), the average MASI score changed to 5.5 \pm 2.7 . The average decrease in the MASI score was 4.2 , and this represent $43 \%$ decrease

\section{Discussion}

The therapy for melasma has always been challenging and discouraging. The current treatments include hypo-pigmenting agents, chemical peels and laser. It is important to avoid exposure to the sun or to ultraviolet lamps and to use broadspectrum sunscreens. Several hypopigmenting agents such as topical hydroquinone $(2-4 \%)$ alone or in combination with tretinoin (0.05-0.1\%) have been used with differing results. Topical azelaic acid (15$20 \%$ ) can be as efficacious as hydroquinone. Kojic acid, alone or in combination with glycolic acid or hydroquinone, has shown good results, due to its inhibitory action on tyrosinase. Laser therapies have not produced completely satisfactory results, because they can induce hyperpigmentation and recurrences can occur ${ }^{(16)}$. The only topical ointment currently approved by the US Food and Drug Administration (FDA) for the treatment of melasma is the Triple Combination Cream, a composite of hydroquinone $4 \%$, tretinoin $0.05 \%$, and fluocinolone acetonide $0.01 \%$. 


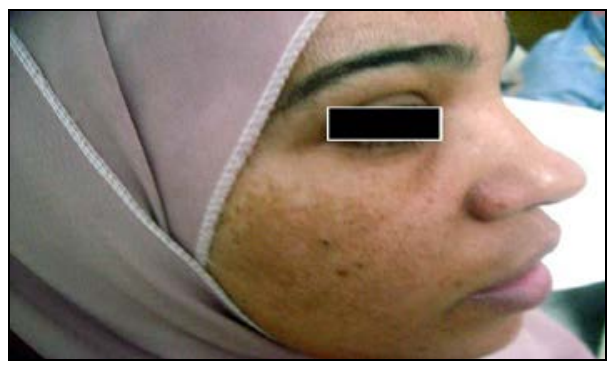

Fig. (1A): TCA treated side at the beginning of sessions.

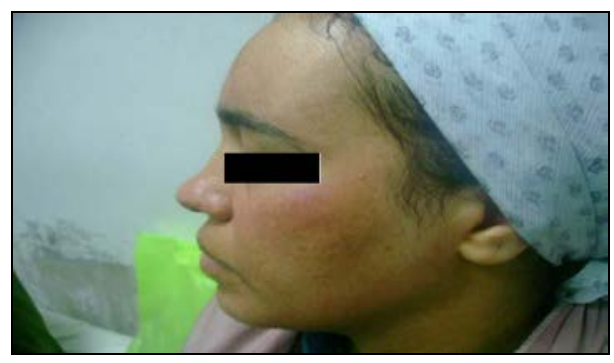

Fig. (1C): Jessner's treated side at the beginning of sessions.

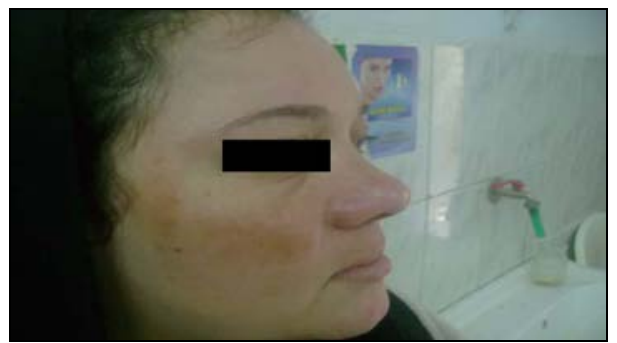

Fig. (2A): TCA treated side at the beginning of session.

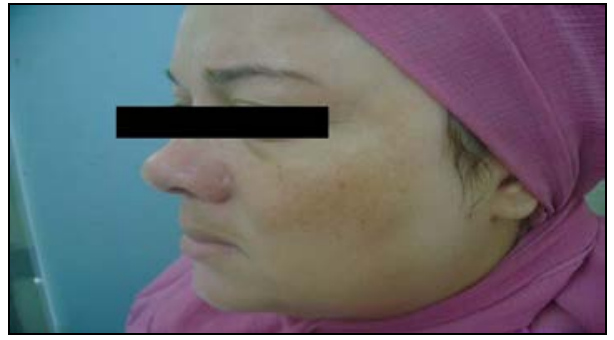

Fig. (2C): Jessner's treated side at the beginning of sessions.

A comparative study by Draelos ${ }^{(17)}$ for the effectiveness of the triple combination cream versus topical hydroquinone (HQ), he suggested that the combination cream is faster and more effective at reducing melasma pigmentation.

Chemical peeling has a low rate of complications and is popular due to the low costs involved and to a technique, which is easy to learn. Chemical peels use-

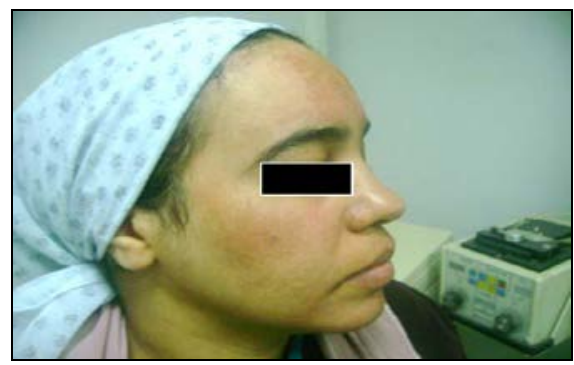

Fig. (1B): TCA treated side at the end of sessions.

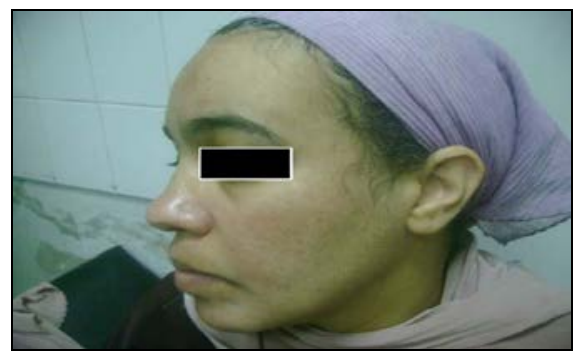

Fig. (1D): Jessner's treated side at the end of sessions.

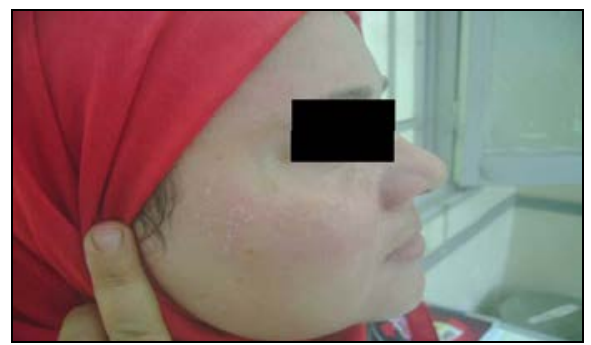

Fig. (2B): TCA treated side at the end of sessions.

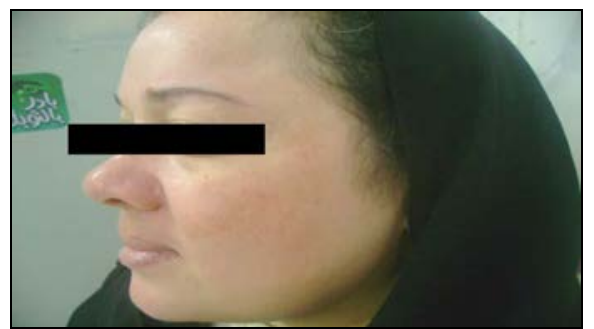

Fig. (2D): Jessner's treated side at the end of sessions.

ful in treating melasma are trichloroacetic acid, Jessner's solution, alpha-hydroxy acid preparations, and salicylic acid alone or in various combinations. These have been found to be particularly useful for melasma of varying severity ${ }^{(16)}$. Priming or preparing the skin for a peel is an important concept in chemical peeling. This helps in a better, uniform penetration of the peeling agent by reducing the sebor- 
rhea and thinning the stratum corneum, accelerates re-epithelization and reduces wound healing time and has a skinlightening effect by enhancing the dispersion of melanin granules throughout the epidermis $^{(18)}$.

Our findings suggest that both TCA and Jessner's solution produced similarly high statistical significant improvement from the base line $(p<0.01)$. We noticed clinical improvement by using both TCA and Jessner's solution after the second visit and this improvement was more evident in the lighter skin types, more rapid improvement was noticed on the TCA treated side, and this was obvious in the lighter skin types. By the end of the sessions, more patients showed a significant improvement of the melasma. Accordingly, on TCA treated side $55.2 \%$ of the patients had excellent improvement, $20.7 \%$ of them had good improvement, this results slightly differs from those found by Valkova ${ }^{(19)}$ who demonstrated that $(62 \%)$ of them assessed therapeutic efficacy as excellent (greater than 90\% improvement) and (31\%) as good (greater than $50 \%$ improvement).

Table 2: Side effects in both TCA and Jessner's solution sides of the face

\begin{tabular}{|c|c|c|c|c|c|}
\hline Side effects & & $\begin{array}{c}\text { TCA }(n=29) \\
\text { No }(\%)\end{array}$ & $\begin{array}{c}\text { Jessner's }(n=29) \\
\text { No }(\%)\end{array}$ & Test & $P$-value \\
\hline Erythema & $\begin{array}{l}\text { - Mild-Moderate } \\
\text { - Severe }\end{array}$ & $\begin{array}{l}13(44.8) \\
16(55.2)\end{array}$ & $\begin{array}{l}10(34.5) \\
19(65.5)\end{array}$ & $0.29^{\$}$ & 0.59 \\
\hline $\begin{array}{l}\text { Discomfort (burning } \\
\text { and/or itching) }\end{array}$ & $\begin{array}{l}\text { - None } \\
\text { - Mild } \\
\text { - Moderate } \\
\text { - Severe }\end{array}$ & $\begin{array}{c}0 \\
2(6.9) \\
7(24.1) \\
20(69) \\
\end{array}$ & $\begin{array}{c}1(3.4) \\
16(55.2) \\
8(27.6) \\
4(13.8) \\
\end{array}$ & $22.6^{\$}$ & $0.000 * *$ \\
\hline Infection & $\begin{array}{l}\text { - None } \\
\text { - Moderate }\end{array}$ & $\begin{array}{c}28(96.6) \\
1(3.4) \\
\end{array}$ & $\begin{array}{c}29(100) \\
0\end{array}$ & Fisher's exact & 0.99 \\
\hline Hyper-pigmentation & $\begin{array}{l}\text { - None } \\
\text { - Mild-Moderate }\end{array}$ & $\begin{array}{c}25(86.3) \\
4(13.7)\end{array}$ & $\begin{array}{c}29(100) \\
0\end{array}$ & Fisher's exact & 0.05 \\
\hline Scaling & $\begin{array}{l}\text { - Mild } \\
\text { - Moderate } \\
\text { - Severe }\end{array}$ & $\begin{array}{c}1(3.4) \\
17(58.6) \\
11(37.9) \\
\end{array}$ & $\begin{array}{c}13(44.8) \\
16(55.2) \\
0 \\
\end{array}$ & $21.3^{\$}$ & $0.000 * *$ \\
\hline Dryness & $\begin{array}{l}\text { - None } \\
\text { - Mild } \\
\text { - Moderate } \\
\text { - Severe }\end{array}$ & $\begin{array}{c}1(3.4) \\
8(27.6) \\
14(48.3) \\
6(20.7) \\
\end{array}$ & $\begin{array}{c}4(13.8) \\
8(27.6) \\
16(55.2) \\
1(3.4) \\
\end{array}$ & $5 \cdot 5^{\xi}$ & 0.14 \\
\hline Swelling & $\begin{array}{l}\text { - None } \\
\text { - Mild }\end{array}$ & $\begin{array}{c}28(96.6) \\
1(3.4)\end{array}$ & $\begin{array}{c}28(96.6) \\
1(3.4)\end{array}$ & Fisher's exact & 1.00 \\
\hline
\end{tabular}

$* *=$ Highly significant $p$-value at $\leq 0.01 ; \$=\chi^{2}$

In comparison we noticed that on the Jessner's solution treated side $44.8 \%$ of the patients had excellent improvement, $27.6 \%$ had good, $27.6 \%$ had fair improvement. Raymond and Ron ${ }^{(20)}$ demonstrated that 31.2\% had excellent improvement, $50 \%$ had good improvement, and $18.8 \%$ had fair improvement. Regarding the side effects in this study we found that 4 patients ( $13.7 \%$ of patients) suffered from hyperpigmentation which subsided in about 4 weeks, hyperpigmentation developed on the TCA treated side of the face as the patients manipulate the crust, this agrees with the study done by Valkova ${ }^{(19)}$ as they found that the hyperpigmentation developed most often around the mouth and on the chin in TCA-treated side of the face probably as a result of the premature desquamation of the epidermis in these regions due to the active contraction of the muscles during speaking and eating. 
Also we found that $69.0 \%$ of the patients suffered from severe discomfort as burning and Itching on the TCA side, in comparison to only $13.8 \%$ on the Jessner's solution Safoury et al., ${ }^{(21)}$ found that $20 \%$ of the patients had severe discomfort on the TCA treated side as they used TCA (15\%). Raymond and Ron ${ }^{(20)}$ found that only $25 \%$ of patients suffered from severe discomfort on the Jessner's-treated side.

After the end of the follow up period, there was a sustained improvement in the Jessner's treated side the mean MASI score at the end of sessions was 5.5 \pm 2.7 and at the end of the follow up period was 5.5 \pm 2.7 . Moreover, in the TCA-treated side the average MASI score at the end of the sessions was $4.9 \pm 2.7$, and at the end of follow up period was $4.9 \pm 2.5$ so there was a slight insignificant improvement after the follow up period in the TCA treated side. This results agree with Raymond and Ron $^{(20)}$ which demonstrated those patients who continued topical therapy partially maintained improvement. Those who stopped using topical therapy experienced relapse, although they were still slightly improved over pretreatment measurements. In our study, we expected that TCA is better than Jessner's peel solution in the term of therapeutic efficacy. However, the study doesn't support this expectation as both jessner's solution and TCA showed statistically-significant results. We also expected that Jessner's solution will be more tolerable and less side effects and the study proved that expectation as the patients preferred the Jessner's solution as it is more tolerable, less irritating and less exfoliating.

Conclusion: Both TCA and Jessner's solution produced similarly high degree of improvement but TCA was less tolerable. As regarding TCA peels, it is very important to choose the suitable patient, as it is more effective, more tolerable with fewer side effects in lighter skin types with a rapid improvement as the patient improves after 2-3 sessions, also the Jessner's solution is effective but the patient should finish the 6 sessions to get the same improvement of the TCA treated side.

\section{References}

1. Montemarano A. Melasma, Medicine; 2003, 25: 1-11.

2. Sanchez NP, Pathak MA and Sato S. Melasma: a clinical, light microscopic, ultrastructural, and immunofloresence study. J Am Acad Dermatol; 2001, 4, 698710.

3. Thappa DM. Melasma (chloasma): A review with current treatment options. Indian J. Dermatol.; 2004, 49: 165-76.

4. Monheit GD. Chemical peels, advances in dermatologic surgery. Skin Ther. Lett.; 2004, 9:6-11.

5. Briden ME. Alpha-hydroxyacid chemical peeling agents: case studies and rationale for safe and effective use. Cutis.; 2004, 73 (2 Suppl):18-24.

6. Sarkar R, Kaur C, Bhalla M and Kanwar AJ. The combination of glycolic acid peels with a topical regimen in the treatment of melasma in dark-skinned patients: a comparative study. Dermatol. Surg.; 2002, 28: 828-32.

7. Hautarzt R. Chemical peels in aesthetic dermatology. Indian J Dermatol.; 2004, 55(7):611-20.

8. Kovach BT and Sengelmann RD. Chemical peels. In:Hirsch RJ, Cohen JL, Sadick N, editors. Regional approach to aesthetic rejuvenation. New York: Dermatology; 2009, 111, 40-48.

9. Rubin MG. Manual of chemical peels: superficial and medium depth. J.B. Lippincott Company, Philadelphia; 1995, pp 79-88.

10. Pathak MA, Fitzpatrick TB, and Kraus EW. Usefulness of retinoic acid in the treatment of melasma. J Am Acad Dermatol; 1986, 15, 894-899. 
11. Chun E, Lee J and Lee K. Focal trichloroacetic acid peels method for benign pigmented lesions in dark-skinned patients. Dermatol Surg; 2004, 30(4): 5126.

12. Antonella T, Pearl E and Grimes P. Color atlas of chemical peel. Springer link; 2006, 23-29.

13. Barbaud A, Modiano P, Cocciale M, Reichert S and. Schmutz J. The topical application of resorcinol can provoke a systemic allergic reaction. Br J Dermatol; 1996, 135, 6, 1014-1015.

14. Kimbrough-Green CK, Griffiths CM and Finkel LJ. Topical retinoic acid (tretinoin) for melasma in black patients. Arch. Dermatol; 1994, 130:727-733.

15. Tuleya S. Feature: melasma update. In: Skin \&Aging - ISSN: 1096-0120, Vol. 11- Issue 10; 2003, Tuleya S (ed). P: 89-91.

16. Pérez-Bernal A. Management of facial hyperpigmentation. Am J Clin Dermatol; 2000, 1, (5), 261-268.
17. Draelos $Z$. The combination of $2 \% 4$ hydroxyanisole (mequinol) and $0.01 \%$ tretinoin effectively improves the appearance of solar lentigines in ethnic groups. J Cosmet Dermatol; 2006, 5(3): 239-244.

18. Sarkar R, Kaur C, Bhalla M and Kanwar AJ. The combination of glycolic acid peels with a topical regimen in the treatment of melasma in dark-skinned patients: a comparative study. Dermatol Surg; 2002, 28: 828-832.

19. Valkova A. Treatment of melasma with glycolic versus Trichloroacetic acid peels. Dermatol. Surg.; 2004, 10.

20. Raymond TK and Ron RY. Chemical peels. Am J Clin Dermatol; 2007, (1), 53-9.

21. Safoury OS, Zaki NM, El Nabarawy EA, Farag EA. A study comparing chemical peeling using modified jessner's solution and $15 \%$ trichloroacetic acid versus 15\% trichloroacetic acid in the treatment of melasma. Indian J. Dermatol.; 2009, 54(1): 41-45. 